\title{
An Experimental Study on Damage Detection of Structures using a Timber Beam
}

\author{
Fook Choon Choi, Jianchun Li, Bijan Samali \& Keith Crews \\ Centre for Built Infrastructure, Faculty of Engineering, University of Technology, Sydney, Australia \\ fookcho@eng.uts.edu.au; Jianchun.Li@uts.edu.au;Bijan.Samali@uts.edu.au; keith.crews@uts.edu.au
}

\begin{abstract}
Using vibration methods for the damage detection and structural health monitoring in bridge structures is rapidly developing. However, very little work has so far been reported on timber bridges. This paper intends to address such shortcomings by experimental investigation on a timber beam using a vibration based method to detect damage. A promising damage detection algorithm based on modal strain energy was adopted and modified to locate/evaluate damage. A laboratory investigation was conducted on a timber beam inflicted with various damage scenarios using modal tests. The modal parameters obtained from the undamaged and damaged state of the test beam were used in the computation of damage index, were then applied using a damage detection algorithm utilising modal strain energy and a statistical approach to detect location of damage. A mode shape reconstruction technique was used to enhance the capability of the damage detection algorithm with limited number of sensors. The test results and analysis show that location of damage can be accurately identified with limited sensors. The modified method is less dependent on the number of modes selected and can detect damage with a higher degree of confidence.
\end{abstract}

\section{Introduction}

Damage detection and structural health monitoring of bridge structures, which increasingly experience deterioration, aging and traffic overloads, have attracted a great deal of attention among researchers. Among various proposed damage detection algorithms, the methods based on vibration of structures have shown great potential. However, not much work has been reported on timber bridges using vibration based methods to detect or to evaluate damage (Peterson et al. 2001a,b). The fact that Australia has approximately 27,000 aging timber bridges (Crews at al. 2004), justifies that a systematic and reasonably sensitive damage inspection, identification and health monitoring schemes are developed for health monitoring of these bridges. Due to this shortcoming, the current project is to contribute to the knowledge of locating/evaluating damage in timber bridges.

It is a challenge to study damage detection in wood products such as timber bridges, which is a complex natural product and system, especially using vibrationbased methods as a global non-destructive damage detection tool. Many methods of damage detection, based on vibration technique, have been developed for civil engineering structures. Some of these methods have shown to be applicable to steel and concrete bridges (Salawu and Williams 1995; Yoon et al. 2001; Morrison et al. 2002; Patjawit and Kanok-Nukulchai 2005). One of the promising methods to detect damage is damage index method developed by Stubbs et al. (1995). This paper has adopted and modified the damage index method, which utilises modal strain energy and a statistical approach, to detect damage in an experimental timber beam under various damage scenarios. 
Fook Choon Choi, Jianchun Li, Bijan Samali \& Keith Crews, 2007, 'An experimental study on damage detection of structures using a timber beam', Journal Of Mechanical Science And Technology, 21, 6, pp. 903-903

\section{Description of test sample}

\section{Undamaged model}

A timber beam was used in the experimental work, which intended to represent the scaled girders of typical timber bridges in Australia. The basic dimensions of the beam are shown in Figure 1. The beam is of treated radiate pine sawn timber measuring $45 \mathrm{~mm}$ by $90 \mathrm{~mm}$ in cross section with a span length of $4,500 \mathrm{~mm}$. A specially designed support system was used between the girder and the concrete supports to provide a well-defined boundary condition that is very close to a pin-pin condition as depicted in Figure 2.

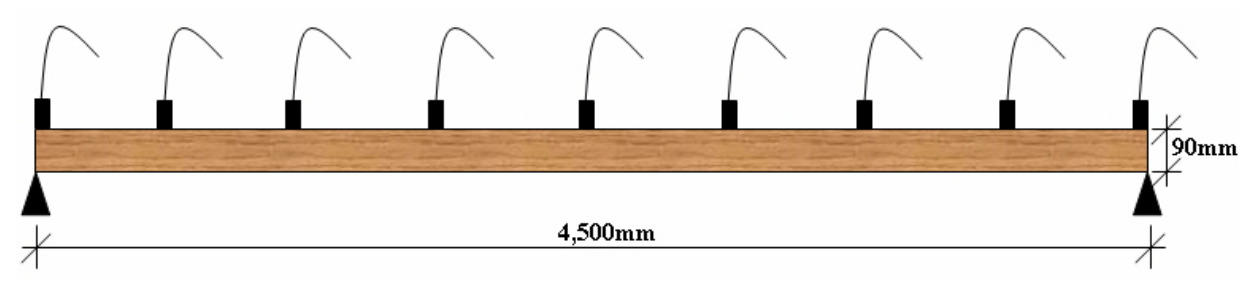

Figure 1. Side elevation of the laboratory timber beam with 9 accelerometers.

\section{Damaged model}

The goal of this study was to detect damage typically found in timber bridges. It is intended to locate damage in multiple locations on a timber beam. The damage cases are described in Table 1 . All damage scenarios consist of a rectangular opening from the soffit of the beam, located at 2/8, midspan, $5 / 8$ and $6 / 8$ of the span length to simulate pockets of rotten wood, which usually starts from the top surface in timber girders. In this paper and the discussions that follow, ' $S$ ' denotes severe damage. All inflicted damage are $1 \%$ of the total span length $(45 \mathrm{~mm})$ and consist of $50 \%$ of the beam depth, designated as damage cases ' $\mathrm{S}$ ' as shown in Table 1. A typical inflicted damage is shown in Figure 3.

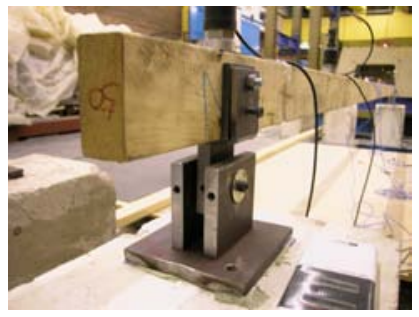

Figure 2. The pin support.

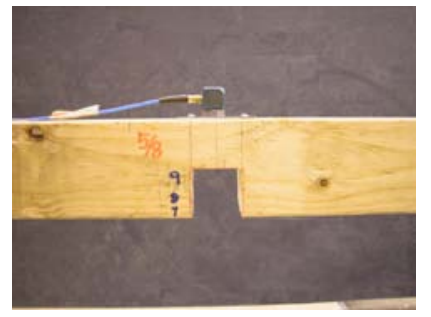

Figure 3. A typical inflicted damage.

\begin{tabular}{|c|c|c|c|c|}
\hline Damage Case & $\begin{array}{c}\text { Location per 8 } \\
\text { of span length }\end{array}$ & $\begin{array}{c}\text { Width } \\
(\mathrm{mm})\end{array}$ & $\begin{array}{c}\text { Depth } \\
(\mathrm{mm})\end{array}$ & \% reduction of 'I' \\
\hline 4S & 4 & 45 & 45 & 87.5 \\
\hline 4S6S & 4,6 & 45 & 45 & 87.5 \\
\hline 4S5S6S & $4,5,6$ & 45 & 45 & 87.5 \\
\hline 2S4S5S6S & $2,4,5,6$ & 45 & 45 & 87.5 \\
\hline
\end{tabular}

Table 1. Dimensions of inflicted damage. 
Fook Choon Choi, Jianchun Li, Bijan Samali \& Keith Crews, 2007, 'An experimental study on damage detection of structures using a timber beam', Journal Of Mechanical Science And Technology, 21, 6, pp. 903-903

\section{Experimental set up}

The instrumentation layout used during the modal tests is shown in Figure 4. An impact hammer was used to excite the beam. Nine accelerometers were used to measure dynamic response of the beam. One of the accelerometers was used as the driving point measurement. Each accelerometer was attached onto a small steel plate using magnetic base and was then screwed onto the top of the girders. These accelerometers were located at 1/8 intervals of the span length starting from one end of the beam as shown in Figure 1. The impact location, at $3 / 4$ of the span length, was selected so that more modes can be excited, simultaneously. The HP E1432A and LMS were used to record the dynamic response at 10,000 $\mathrm{Hz}$ sampling rate for 8,192 data points. Frequency domain direct measurement curve-fitting technique was used to obtain the eigenvalues and eigenvectors of the measured data. From the experimental tests, five vibration modes were captured. The resulting mode shapes are shown in Figure 5. It should be noted that the fourth flexural mode (mode 4) was not very good because the impact location falls on its inflection point. Nevertheless, this mode was still used in the subsequent discussions.

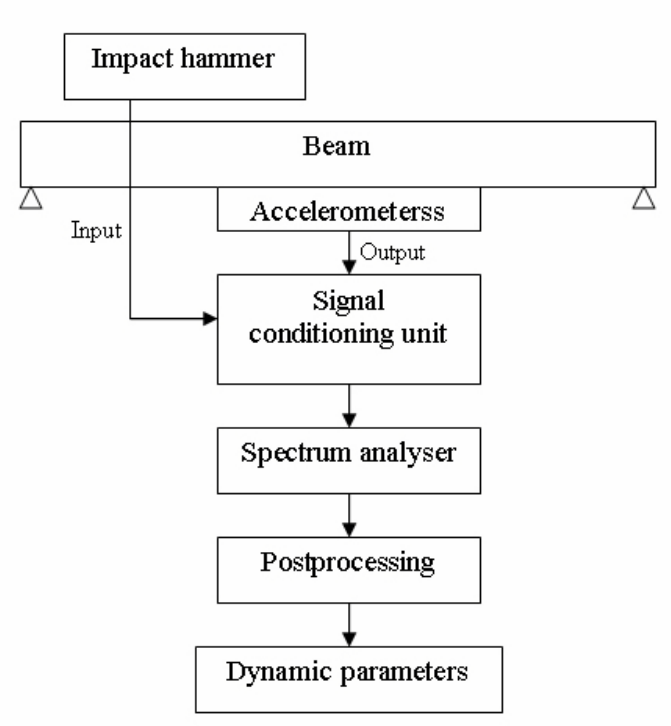

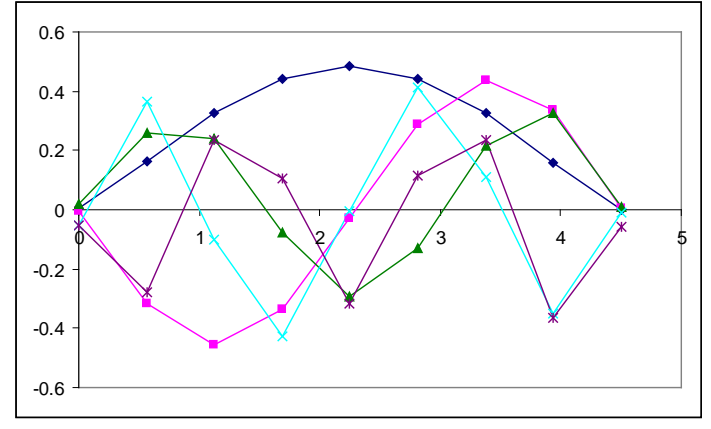

Figure 5. Experimental mode shapes

Figure 4. Instrumentation used for modal test

\section{Modified Damage Index (MDI)}

The derivation of Equation 1, in more details, is discussed in Li et al. (2005). In this equation, the terms $\bar{\phi}_{i}^{/ / *}$ or $\bar{\phi}_{i}^{\prime \prime}$ are normalized mode shape curvature coordinates, which are normalised with respect to the maximum value of the corresponding mode of the beam. The asterisk denotes the damage cases.

$$
\overline{\beta_{i j}}=\frac{\left.\left[\int_{j}\left\{\bar{\phi}_{i}^{\prime \prime *}(x)\right\}^{2} d x+\int_{0}^{L}\left\{\bar{\phi}_{i}^{\prime \prime *}(x)\right\}^{2} d x\right]\right]_{0}^{L} \int_{0}^{L}\left\{\bar{\phi}_{i}^{\prime \prime}(x)\right\}^{2} d x}{\left.\left[\int_{j} \bar{\phi}_{i}^{\prime \prime}(x)\right\}^{2} d x+\int_{0}^{L}\left\{\bar{\phi}_{i}^{\prime \prime}(x)\right\}^{2} d x\right] \int_{0}^{L}\left\{\bar{\phi}_{i}^{\prime \prime *}(x)\right\}^{2} d x}
$$


The modified damage index method above has been introduced to account for all available mode shapes. The mode shape vectors have been normalised with respect to the Euclidean norm of the matrix. A cubic spline data interpolation function, provided in Matlab program, was used to perform mode shape reconstruction for the experimental data. Nine experimental mode shape points were acquired and were expanded to 41 data points using reconstructed mode shape technique, which would provide a better accuracy on damage localisation. The reconstructed mode shape was then numerically differentiated to obtain mode shape curvature. This was followed by normalisation of the mode shape curvatures used for the damage index calculation. The importance of the normalisation steps is that the summation of non-normalised mode shape curvatures will distort the damage index in favour of higher modes, which results in false damage detections. Transforming the damage indicator values into the standard normal space, the normalized damage index $Z_{j}$ is obtained as follows:

$$
Z_{j}=\frac{\bar{\beta}_{j}-\mu \bar{\beta}_{j}}{\sigma_{\bar{\beta}_{j}}}
$$

where ${ }^{\mu} \bar{\beta}_{j}=$ mean of $\bar{\beta}_{j}$ values for all j elements and ${ }^{\sigma_{\bar{\beta}_{j}}}=$ standard deviation of $\bar{\beta}_{j}$ for all j elements.

\section{Experimental results}

In the following results, the statistically normalised damage indicator values ( $\mathrm{Zj})$ for each of the damage cases are plotted against the element number. The actual damage locations are indicated with dashed lines in all figures.

The damage detection of single damage case 4S, using 2 and 5 modes to compute the modified damage index (MDI), are shown in Figures $6 a$ and $6 \mathrm{~b}$, respectively. The damage region is picked up by the Damage Detection (DD) algorithm. However, there are some "false indications of positive damage locations" (referred to as false positive) in both Figures $6 \mathrm{a}$ and 6b. The latter provides a higher confidence in detecting the damage as there is only one false positive and it is negligible. The false positive may be attributable to noise present in the experimental data, which does not appear in the numerical simulation results (not quoted in this paper). It is apparent that the MDI is capable of identifying the location of single damage and combination of higher modes depicts a more precise DD.

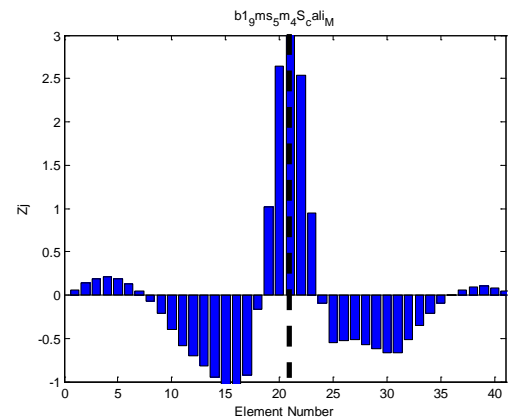

Figure 6a. Damage Case 4S (2 modes).

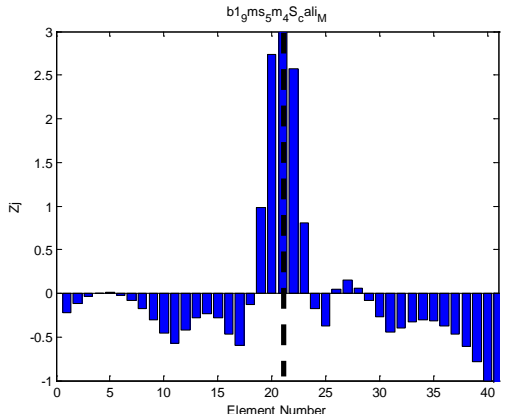

Figure 6b. Damage Case 4S (5 modes). 
Similar process of DD was applied to the multiple damage scenarios. The results of damage detection for 2, 3 and 4 damage locations are illustrated in Figures $7 \mathrm{a}$ to $7 \mathrm{f}$, respectively. All damage locations were successfully located by the DD algorithm computed using 5 modes despite the very few and low level of false positive. The false positive near the support may have been caused by the mode shape reconstruction technique. However, the MDI computed with 2 modes has missed one damage location (6/8 ${ }^{\text {th }}$ of the span length) for the Damage Case 2S4S5S6S (see Figure 7e). This may be due to the fact that higher flexural modes have shorter wavelength compared to lower modes, whereby shorter wavelength is more capable to capture closely spaced damage. In the 2 damage location case (see Figures $7 \mathrm{a}$ and $7 \mathrm{~b}$ ), the probability of detecting the damage is quite similar for the two damage locations with the same damage intensity. However, for 3 and 4 damage location cases (see Figures 7c to 7f), the mid-span damage was more pronounced than others. This may be caused by the close spacing of damage locations, which affect the mode shape more as it gets closer to the supports.

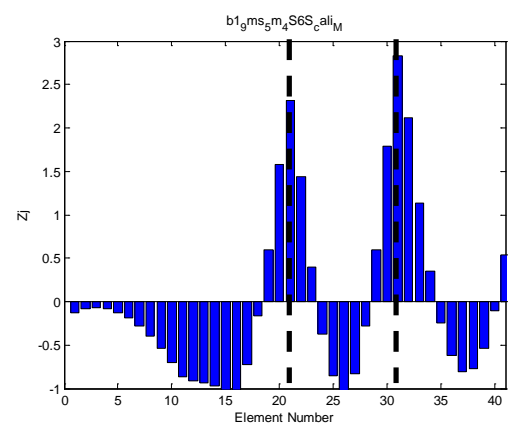

Figure 7a. Damage Case 4S6S (2 modes).

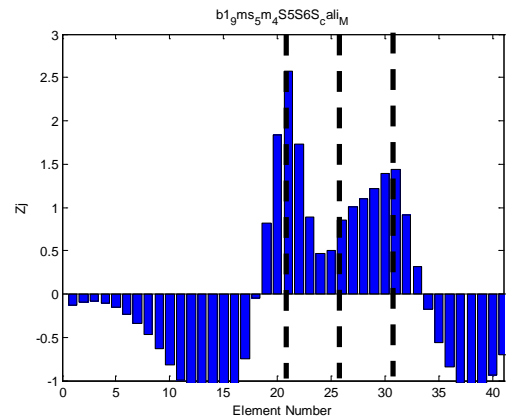

Figure 7c. Damage Case 4S5S6S (2 modes).

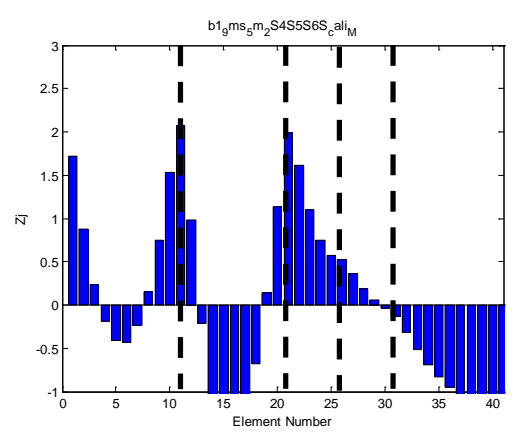

Figure 7e. Damage Case 2S4S5S6S (2 modes).

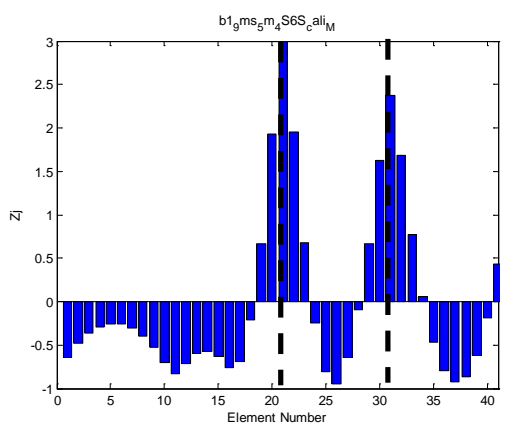

Figure 7b. Damage Case 4S6S (5 modes).

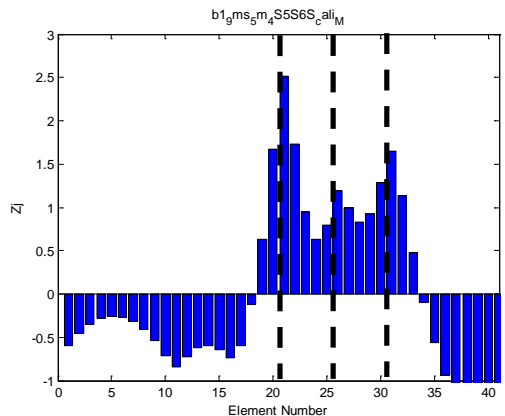

Figure 7d. Damage Case 4S5S6S (5 modes).

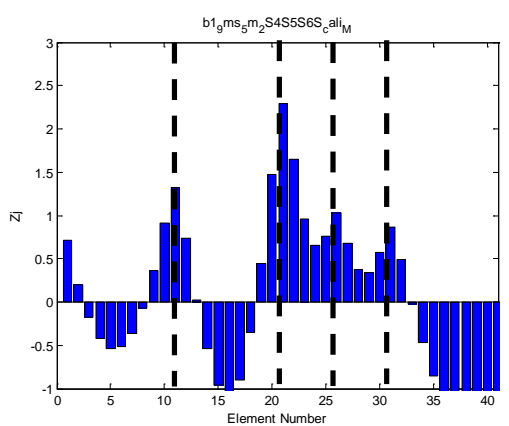

Figure 7f. Damage Case 2S4S5S6S (5 modes). 
Fook Choon Choi, Jianchun Li, Bijan Samali \& Keith Crews, 2007, 'An experimental study on damage detection of structures using a timber beam', Journal Of Mechanical Science And Technology, 21, 6, pp. 903-903

\section{Conclusion}

The modified damage index (MDI) is capable of detecting the damage locations from the experimental data, which is usually polluted by noise, for both single and multiple damage scenarios. The results also show that the damage detection (DD) algorithm, in general, is less 'mode dependent'. However, combination of higher modes is more favourable to detect multiple damage locations, which are closely spaced. With this development, it is possible to further explore the $\mathrm{DD}$ algorithm to estimate the severity of damage, especially in multiple damage scenarios.

\section{Acknowledgement}

The authors gratefully acknowledge the financial assistance provided by the Centre for Built Infrastructure Research (CBIR), of the Faculty of Engineering, University of Technology Sydney. The authors wish to also thank the staff of UTS Structures Laboratory for their assistance in conducting the experimental works.

\section{References}

Crews K, Samali B, Bakoss S \& Champion C. (2004) Overview of assessing the load carrying capacity of timber bridges using dynamic methods. $5^{\text {th }}$ Austroads Bridge Conference May 2004, Tasmania.

Li, J., Samali, B., Choi, F.C. \& Dackermann, U. 2005. Damage identification of timber bridges using vibration based methods. Proceedings of the $11^{\text {th }}$ Asia-Pacific Vibration Conference, Langkawi, Malaysia: 662-668.

Morison A, VanKarsen CD, Evensen HA, Ligon JB, Erickson JR, Ross RJ \& Forsman JW. (2002) Timber bridge evaluation: A global non-destructive approach using impact generated FRFs. Proceedings of the IMAC-XX, Los Angeles, US: 1567-1573.

Yoon MK, Heider D, Gillespie Jr JW, Ratcliffe CP \& Crane RM. (2001) Local damage detection using a global fitting method on mode shape data. Proceedings of the IMAC-XIX, Kissimmee, Florida, US: 231-237.

Peterson, S.T., McLean, D.I., Symans, M.D., Pollock, D.G., Cofer, W.F., Emerson, R.N. \& Fridley, K. 2001a. Application of dynamic system identification to timber beam: I. Journal of Structural Engineering, 127 (4): 418-425.

Peterson, S.T., McLean, D.I., Symans, M.D., Pollock, D.G., Cofer, W.F., Emerson, R.N. \& Fridley, K. 2001b. Application of dynamic system identification to timber beam: II. Journal of Structural Engineering, 127 (4): 426-432.

Salawu OS \& Williams C. (1995) Bridge assessment using forced-vibration testing. Journal of Structural Engineering, 121(2), 161-173.

Stubbs, N., Kim, J. T., and Farrar, C. R. 1995. Field verification of a non-destructive damage localization and severity estimation algorithm. Proceedings of 13th International. Modal Analysis Conference, Nashville, Tenn.: 210-218. 